\title{
Industry Involvement in the Creation and Funding of the eXtension Grape Community of Practice
}

\author{
Eric T. Stafne ${ }^{1,6}$, Edward W. Hellman ${ }^{2}$, R. Keith Striegler ${ }^{3}$, \\ James A. Wolpert ${ }^{4}$, and Jean-Mari Peltier ${ }^{5}$
}

Additional Index words. Cooperative Extension Service, Specialty Crops Research Initiative, National Grape and Wine Initiative

SuMmaRY. Industry involvement is a critical aspect of the Specialty Crops Research Initiative (SCRI). Both a mandate for need and funding are necessary from industry to develop a successful SCRI project. The National Grape and Wine Initiative (NGWI), a nationwide coalition representing all segments of the grape (Vitis sp.) industry including raisin, juice, fresh grape and wine interests, identified extension education as a critical need and charged its extension/outreach committee to concentrate on ensuring industry members are aware of and have access to findings from grape and grape products research. To achieve this goal, the committee decided that a comprehensive online information and educational resource would play an important role. In 2009, the eXtension Grape Community of Practice (GCoP) was funded by the SCRI. The NGWI was active in soliciting letters of endorsement and buy-in from the industry for the project. The Missouri Wine and Grape Board (MWGB) also contributed \$20,000 per year for three years to help offset the matching requirement. Research-based grape proposals in subsequent rounds of the SCRI in 2010 and 2011 wishing to have the approval of NGWI have been strongly encouraged to include the GCoP as a portion of their extension component. For the 2011 round of SCRI proposals, this led to the GCoP being included in three projects, two of which were funded. Exploration of future avenues for funding will include subcontracts from other grant awards, NGWI, industry sponsorships, and other creative methods.

$\mathrm{T}$ he plan to develop a GCoP was generated by the Extension and Outreach Education Committee of the NGWI. The NGWI is a national organization which collaborates to prioritize research for grape products. Comprised of leaders from all sectors of the U.S. grape industry, NGWI includes representatives from wine, juice, table grape, and raisin commodity sectors from all U.S. growing regions. Since its inception, one of NGWI's primary priorities has been extension and education, concentrating on ensuring that industry members are aware of, and have access to, findings from grape and grape product research.

The Extension and Outreach Education Committee of NGWI examined ways to improve Cooperative Extension's ability to meet clientele needs. At six previous National Viticulture Extension Leadership Conferences (2006-11), discussions focused on potential opportunities for national or regional collaborative projects that could further extension efforts and enhance overall program effectiveness. This committee addressed an overall priority of NGWI to enhance outreach education for grape producers by targeting development of a GCoP for the eXtension system (eXtension, 2012) via the SCRI of the U.S. Department of Agriculture (USDA) and the Cooperative State Research, Education, and Extension Service (CSREES).

\section{Historical context}

In 2003, 20 leaders and key stakeholders from the California grape and wine industry and the University of California at Davis Department of Viticulture and Enology met to address a growing crisis in extension and research funding, and to develop a process for establishing priorities that would mutually benefit the wine industry and academic and research organizations across the United States. The meeting participants also identified their vision for the future of grape and wine research and funding. The vision acknowledged that the current state of industry funded research would change through a collaborative initiative between the grape and wine industry, university research institutions, USDA, and other institutions to assure that the U.S. industry would be the worldwide leader in wine science, innovation, economic issues, and environmental and business practices (J-M. Peltier, unpublished data). As a result of this meeting, the participants agreed to develop the Winegrower's Critical Research Investment Initiative (WCRII).

To improve wine and grape production in the United States, the organization created an integrated plan based on specific needs for technology development and strong outreach education programs that would provide technology transfer to grape producers, processors, and wineries. The key areas of research focus include 1) understanding and improving quality, 2) consumer insights and nutrition, 3) production and processing efficiency, 4) sustainable vineyard practices, and 5 ) extension and outreach.

In 2005, the WCRII changed its name to the National Grape and Wine Initiative. The name of the organization changed, but the vision and goals remained the same. The role of NGWI was to take a look at the larger-scale topics that affect the entire industry and can only be addressed by working together on a national level. The focus was on the larger goals that benefit the whole grape industry and its sustainability in the future (J-M. Peltier, unpublished data).

\section{Creation of the GCoP}

In 2009, the GCoP was formed with funding from USDA-CSREESSCRI grant with eXtension as the hosting entity. The leadership team was formed through the NGWI Extension and Outreach Education Committee. This committee addressed an overall priority of NGWI to enhance outreach education for grape producers by targeting development of

\begin{tabular}{llll}
\hline $\begin{array}{l}\text { Units } \\
\text { To convert U.S. to SI, } \\
\text { multiply by }\end{array}$ & U.S. unit & SI unit & $\begin{array}{l}\text { To convert SI to U.S., } \\
\text { multiply by }\end{array}$ \\
\hline 3.7854 & gal & L & 0.2642
\end{tabular}


a GCoP for the eXtension system. The GCoP is currently comprised of a North America-based group of professionals with expertise in commercial grape production. To date, the GCoP has 89 members from 30 states and Canada, who interact through a variety of online methods to collaboratively create content on the eXtension website (eXtension, 2012). The GCoP intends to be inclusive rather than exclusive with other disciplines and is interested in including any qualified participant. Some of the expected outcomes for the GCoP are to: become a comprehensive online resource for research-based viticulture information for grape producers; create links to all state-based websites; integrate projects to increase networking, collaboration, colearning, and reduce redundancy; and to create innovative learning opportunities. The eXtension Grape website became available to the public on 27 Dec. 2010, with an official launch at the Unified Grape and Wine Symposium on 27 Jan. 2011. The GCoP also launched a companion portal website called eViticulture, which leads users directly to viticulture-related information on the eXtension website without the need to navigate through other unrelated content.

This paper was approved for publication as Journal Article No. 12127 of the Mississippi Agricultural and Forestry Experiment Station, Mississippi State University.

This paper was part of the workshop "The Growing Involvement of Horticulture in eXtension: Updates and Opportunities" held 27 Sept. 2011 at the ASHS Conference, Waikoloa, HI, and sponsored by the eXtension (EEXT) Working Group.

Partial funding of this project was provided by the USDA-CSREES-SCRI award no. 2009-51181-06084.

The mention of trade name or commercial products in this article is solely for the purpose of providing specific information and does not imply recommendation or endorsement to the exclusion of other products that may also be suitable.

${ }^{1}$ Assistant Extension Professor, Coastal Research and Extension Center, Mississippi State University, South Mississippi Branch Experiment Station, 810 Hwy 26 West, Poplarville, MS 39470-7472

${ }^{2}$ Professor, Texas AgriLife Extension Service Agricultural Research and Extension Center, 1102 E. FM 1294 Lubbock, TX 79403-6603

${ }^{3}$ Former Associate Professor, Institute for Continental Climate Viticulture and Enology, Division of Food Systems and Bioengineering, College of Agriculture, Food, and Natural Resources, 108 Eckles Hall, University of Missouri-Columbia, Columbia, MO 65211-5140

${ }^{4}$ Viticulture Extension Specialist, Viticulture and Enology Department, University of California Davis, One Shields Avenue, Davis, CA 95616-5270

${ }^{5}$ President, National Grape and Wine Initiative, 1415 L Street, Suite 460, Sacramento, CA 95814-3964

${ }^{6}$ Corresponding author. E-mail: estafne@ext.msstate.edu.
The mission of the GCoP is to strive to meet the educational needs of the grape industry as a whole, including industry partners, extension educators, and consumers by providing science-based information and learning opportunities through eXtension. This means that any professional viticulturist, hobbyist, or consumer will have access to information about any aspect of growing and producing grapes at any time on any Internet-ready device and, by doing so, will increase their knowledge and use the information as a way to improve their skills, life, and/ or business.

\section{Funding of the GCoP}

Funding of extension projects has been a struggle for quite some time (Hochmuth and Maynard, 2002), regardless of the level of financial need. However, for a project of national scope the issue can quickly become acute. It is expensive to run a community of practice (CoP), upwards of $\$ 50,000$ per year, although that number is dependent upon many factors. Several core needs must be met for the CoP to succeed, including employing a project coordinator, forming committees, holding conferences, recruiting new members, training members, and editing, publishing, and evaluating content. The initial SCRI grant facilitated the growth, engagement, and early success of the GCoP; however, industry involvement is a critical, required aspect of SCRI proposals and committed involvement is not always easily obtained. Extension projects are often perceived in a different light than research projects by both the academic and industry communities. So far, industry has not been a significant source of funds for the GCoP, but this avenue is just now being explored.

The MWGB expressed their support for the GCoP in the form of a financial match to the original grant. The MWGB is funded by a $\$ 0.12$ per gallon tax on wine sales. Other than those funds, no financial support has come from other states including California, Washington, Oregon, or New York-the states producing the most grapes. This type of "door-to-door" fundraising is timeconsuming and GCoP members have neither the time nor the acumen to fully delve into this task. In Fall 2010, the NGWI Board pledged assistance and eXtension is exploring new opportunities as well.

The efforts of NGWI to secure increased funding for viticulture research and extension is an ongoing endeavor. Each year NGWI collaborates to prioritize research for the grape and grape product industries, and works to secure increased government, academic, and private sector funding to address these important needs. Committees within NGWI then work to ensure research findings are made available to industry members through outlets like the GCoP. Continued GCoP funding and leadership will be provided through creative public-private partnerships among government, academic, nonprofit, and private sector partners accountable for research, development, and adoption of business, environmental, and socially responsible best practices in the American grape and wine industry.

Successes. The SCRI has provided a vital source of funding for viticulture research issues of national and regional importance. The NGWI research and extension theme committees involve industry members and several individuals cross-participate in multiple committees. This type of cross-pollination aids the integration of extension within existing and new projects. The cross-integration of committees within NGWI has benefited the GCoP, as new proposals are strongly encouraged to become linked to the GCoP for part of their outreach component. Through this process, SCRI funds have been allocated to two projects that have included the GCoP as part of their outreach component: "Accelerating grape cultivar improvement via phenotyping centers and next generation markers" (B.I. Reisch, project director) and "Northern grapes: Integrating viticulture, winemaking, and marketing of new cold-hardy cultivars supporting new and growing rural wineries" (T.E. Martinson, project director). The subawards generated from these projects will help to sustain the GCoP for a short period beyond the original establishment grant, but more funding is needed.

The real success of the GCoP has been increased collaboration among viticulturists on a national and international scale. Before the GCoP, 
interaction of viticulture specialists usually occurred on a state or regional basis. The GCoP facilitates members learning from each other and encourages collaboration on publications that strengthen the work, such as an article published by Westover and Wolpert (2011) on grapevine problems. Authors may work in two different states, different environments, and with different varieties, but by combining their collective knowledge, the resulting publication is more comprehensive and more applicable to a wider audience. Many of these articles have been translated into Spanish as well to reach a broader audience. Data collected from Google Analytics show that content from the eXtension grape website has been viewed more than 135,000 times during 2011 . This number is encouraging for the first year. The eXtension system also enables content to be readily updated as needed, a feature that is a significant advantage over traditional extension publications.

Challenges. A key challenge to managing a $\mathrm{CoP}$ is keeping members engaged and active. One of the recurring laments of members is that they lack the time to fully participate. Lack of time can be taken at face value or in terms of priority, where the member does not prioritize the work of the national community as high as that of their own state.

Land-grant universities across the country are contributing monetary funding to ensure that eXtension continues, but there is no directive, encouragement, or recognition by many land-grant universities for faculty participation in the eXtension initiative, a problem identified by others (Kelsey, 2011; Pankow and O'Neill, 2008; Sellers et al., 2009). In fact, the vision for eXtension from administrators may vary from that of specialists (Hoag, 2005), who need recognition for their efforts. The information provided on the eXtension website is researchbased, unbiased, and reviewed, which are key elements and advantages of Cooperative Extension (Hoag, 2005). Yet, very few universities incorporate eXtension into their promotion and tenure value system and thus contributors are left to weigh whether to spend time on eXtension content vs. traditional extension materials. Until eXtension work is recognized on par with work done at a state or national level in other areas, the GCoP will not be a priority for most participants because of lack of incentive (Kelsey, 2011; Pankow and O'Neill, 2008; Sellers et al., 2009).

Obtaining industry feedback is also an area of difficulty. Traditional surveys are a common way to assess impact, but often response is poor. New methods of conducting surveys are now available that instantly generate feedback. Greene et al. (2010), for example, implemented instant surveys during webinars or other online presentations to gauge the success of the program and the impact of the education received by the student. These researchers also described anecdotal impact information given via social media sites maintained by the CoP. Even though these new methods of impact assessment are available, the users must respond to make it useful. For a 6-month period in 2010, the GCoP implemented an online survey by providing a link on specific articles. That survey only generated 72 responses from 20 states; therefore, more options are being explored to generate better survey feedback.

Future. A strategic plan developed by NGWI includes pursuit of a "USDA Grape Initiative" with USDA through a new and innovative collaboration of the USDA Agricultural Research Service, National Institute of Food and Agriculture, and NGWI. A grape initiative would focus on existing funds to better align all grape research support-federal, state, and private industry - with the most significant needs of the industry. Working closely with USDA, land-grant universities, and other researchers, NGWI hopes to create a template of how to assure that scarce research assets are spent on the most pressing issues facing the U.S. grape and grape products industry.

\section{Conclusions/lessons learned}

The GCoP was initially funded through an SCRI grant for three years. Subsequent funding has come from SCRI grants, but at levels that do not sustain the project. To be sustainable in the longer term, funding must be obtained from external sources (industry) or generated from internal sources (online courses, smart phone applications, etc.). The level of funding will greatly impact how, when, and what kind of products are ultimately developed. Also integral to this discussion is this question, "At what level should extension be expected to continue funding this project?" So far, the GCoP leadership has garnered funds to initiate the project as well as "piggy-back" onto other projects that create funding to assist with the project.

The eXtension GCoP is dedicated to delivering the highest quality, research-based, peer-reviewed material for viticulturists. The initial SCRI project has been successfully executed by creating a with 89 members from around the country (and Canada) and having launched the eViticulture website. Yet, conveying "success" and "value" to industry and university administrators is paramount if the $\mathrm{GCoP}$ is to continue in the long-term.

\section{Literature cited}

eXtension. 2012. eXtension. 27 Jan. 2012. <http://www.extension.org/>.

Greene, E.A., A.S. Griffin, J. Whittle, C.A. Williams, A.B. Howard, and K.P. Anderson. 2010. Development and usage of eXtension's HorseQuest: An online resource. J. Anim. Sci. 88:2829-2837.

Hochmuth, G.J. and D.N. Maynard. 2002. Generating private-sector funding for extension programs. HortTechnology $12: 495-498$.

Hoag, D.L. 2005. Economic principles for saving the cooperative extension service. J. Agr. Res. Econ. 30:397-410.

Kelsey, K.D. 2011. Development of a grape community of practice for the eXtension system: Evaluation report year two. 10 Jan. 2012. <http://create. extension.org/sites/default/files/ GrapeCoPEvaluationReport2011.pdfs.

Pankow, D. and B. O’Neill. 2008. eXtension financial security for all: A community of practice to increase financial literacy. J. Ext. 46(3) <http://www.joe.org/joe/ 2008june/a3.php>.

Sellers, D.M., A.B. Crocker, A. Nichols, S.D. Kirby, and M. Brintnall-Peterson. 2009. Creating the eXtension family caregiving community of practice. J. Ext. $47(5)<$ http://www.joe.org/joe/ 2009 october/al.php>.

Westover, F. and J.A. Wolpert. 2011. Grapevine problems: Leaf spots not caused by insects or diseases. eXtension Grape Community of Practice. 10 Jan. 2012. <http://www.extension.org/pages/ 31599/grapevine-problems:-leaf-spotsnot-caused-by-insects-or-disease $>$. 